\title{
Congenital enterocyte heparan sulfate deficiency
}

INSERM

\section{Source}

INSERM. (1999). Orphanet: an online rare disease and orphan drug data base. Congenital enterocyte heparan sulfate deficiency. ORPHA:103910

Congenital enterocyte heparan sulphate deficiency is characterised by massive enteric protein loss, secretory diarrhoea, and intolerance to enteral feeds during the first few weeks of life. 